\title{
KNOWLEDGE, PRACTICE AND ACCEPTANCE OF CONTRACEPTIVES AMONG MTP SEEKERS
}

\author{
Manasi Patnaik1, Sushreesmita Mohanty², Rakesh Kumar Maharana ${ }^{3}$
}

${ }^{1}$ Associate Professor, Department of Obstetrics and Gynaecology, KIMS, Bhubaneswar.

${ }^{2}$ Associate Professor, Department of Obstetrics and Gynaecology, Hi-Tech Medical College and Hospital, Bhubaneswar.

${ }^{3}$ Postgraduate Student, Department of Obstetrics and Gynaecology, Hi-Tech Medical College and Hospital, Bhubaneswar.

\section{ABSTRACT}

\section{BACKGROUND}

Unplanned pregnancy is the reason behind majority of MTPs in a developing and overpopulated country like India. The unmet need for contraception still poses a challenge despite the best efforts of the Government and other Non-Government Organisations. So counselling regarding knowledge and use of contraception should be an integral part of post-abortion care. Only with counselling can the acceptance of contraceptive be increased in women of reproductive age. Thus, unwanted pregnancies and the risks involved due to unsafe abortion in many cases can be avoided.

The aim of this study is to study the knowledge and awareness of contraceptives and assess their acceptability in women seeking medical termination of pregnancy (MTP) at two tertiary health centres in Bhubaneswar.

\section{MATERIALS AND METHODS}

A cross-sectional study of 257 women seeking MTP in two tertiary care hospitals in Bhubaneswar. Data regarding awareness of contraception and their acceptance in post-abortion period was collected using a pre-structured questionnaire.

\section{RESULTS}

Majority of women seeking MTP had two or more living children (68.1\%) and were between 21 - 30 years of age (64.2\%). Most of them had prior knowledge of contraception excepting few (8.1\%). Commonest reason for not using them was fear of side effects. All the women were counselled prior to discharge and most of them (89.2\%) agreed to adapt birth control methods.

\section{CONCLUSION}

Unmet need of contraception is the most common reason for women having unplanned pregnancy. Though the awareness of different methods of contraception is high, the actual acceptance rate is low. Hence, there is a need for community health education to inculcate proper knowledge and ensure their use in the target population.

\section{KEYWORDS}

Unplanned Pregnancy, Abortion, Contraceptive, Unmet Need.

HOW TO CITE THIS ARTICLE: Patnaik M, Mohanty S, Maharana RK. Knowledge, practice and acceptance of contraceptives among MTP seekers. J. Evolution Med. Dent. Sci. 2017;6(87):6021-6024, DOI: 10.14260/jemds/2017/1309

\section{BACKGROUND}

India is the second most populous country in the world. Unintended or unplanned pregnancy poses a major economical, psychological, social and/or religious challenge in women of reproductive age, especially in developing countries. Induced abortion is an important part of women's reproductive health. It has been estimated that of the 210 million pregnancies that occur annually worldwide, about 80 million (38\%) are unplanned and 46 million (22\%) end in abortion.[1] Contraceptive counselling and the provision of contraceptive methods should be an integral part of any abortion care or post-abortion care to help women avoid another unplanned or unwanted pregnancy and the risk in many cases of an unsafe abortion. It is for this reason that post-abortion contraception is one of the strategies proposed by the International Federation of Gynaecology and Obstetrics (FIGO) initiative for the prevention of unsafe abortion and its consequences.[2] This unmet need for contraception still poses a challenge despite the best efforts of the Government and other Non-Government Organisations.

'Financial or Other Competing Interest': None.

Submission 09-10-2017, Peer Review 22-10-2017,

Acceptance 24-10-2017, Published 30-10-2017.

Corresponding Author:

Dr. Sushreesmita Mohanty,

Friends Colony, Bajrakabati Road,

Cuttack-753001.

E-mail: drsushreesmita98@gmail.com

DOI: $10.14260 /$ jemds $/ 2017 / 1309$
Aims and objectives

- To study the obstetric profile of women seeking abortion in different age groups.

- To find out the awareness of contraceptives and reasons for not accepting any prior to abortion.

- To assess the acceptability of contraception following post-abortion counselling.

\section{MATERIALS AND METHODS}

A cross-sectional study was carried out in women seeking MTP at the outpatient departments of two tertiary health care centres in Bhubaneswar.

Inclusion criteria was women in the age group of 15 - 45 years, who were pregnant and were seeking MTP. Data was collected using a pre-structured questionnaire which included questions regarding the obstetric profile, awareness of contraceptives and reasons for not using any methods of contraception. Only those women willing to participate in the study were included in the study group.

This data was collected over a period of two years from January 2014 to December 2016. The responses of the participants to the questions were analysed and the data was expressed in proportions and percentages.

\section{RESULTS}

A total number of 257 women between January 2014 and December 2016 came to the outpatient department of Obstetrics and Gynaecology at two tertiary health centres of 
Bhubaneswar seeking MTP and were willing to participate in the study. Majority of the women were between 21 and 30 years of age (64.2\%). A total of 75 women were aged between 31 to 40 years $(29.2 \%)$ and only 3 of them were above 41 years $(1.2 \%) ; 14$ women $(5.4 \%)$ were less than 20 years and were included in the adolescent age group (Table I).

\begin{tabular}{|c|c|c|}
\hline Age & Frequency & Percentage \\
\hline$<20$ yrs. & 14 & 5.4 \\
\hline $21-30$ yrs. & 165 & 64.2 \\
\hline $31-40$ yrs. & 75 & 29.1 \\
\hline$>41$ yrs. & 03 & 1.2 \\
\hline \multicolumn{2}{|c|}{ Table I. Distribution of Women according to Age } \\
\hline
\end{tabular}

The obstetric profile of these women showed that a majority 175 (68.1\%) were having two or more living children, 53 (20.6\%) had one living child only, while 29 $(11.3 \%)$ had no children or were primi gravida (Table II).

\begin{tabular}{|c|c|c|}
\hline Parity & Frequency & Percentage \\
\hline P0 & 29 & 11.2 \\
\hline P1 & 53 & 20.6 \\
\hline P2 and Above & 175 & 68.1 \\
\hline Table II. Distribution of Women according to Parity \\
\hline
\end{tabular}

Knowledge and awareness of different methods of contraception among these women were assessed and it was found that most of them knew about one or more forms of contraceptive methods and only a mere $8.1 \%$ (21) were not aware of any contraceptive practices. Maximum number of women 198 (77\%) had knowledge about condoms and 172 $(66.9 \%)$ were aware of oral contraceptives. Many of them, $164(63.8 \%)$ and 142 (55.2\%) women knew about female sterilisation and intrauterine contraceptive devices respectively. Around 126 women (49.0\%) adopted natural methods of contraception at some point of time; 64 (24.51\%) women were aware of male sterilisation operation and few women had some knowledge about DMPA injection (19.8\%) and emergency contraceptives (14.39\%) (Table III).

\begin{tabular}{|c|c|c|}
\hline Types & Frequency & Percentages \\
\hline Condom & 198 & 77 \\
\hline Oral contraceptive pills (OCP) & 172 & 66.9 \\
\hline $\begin{array}{c}\text { Intrauterine contraceptive } \\
\text { devices (IUCDs) }\end{array}$ & 142 & 55.2 \\
\hline $\begin{array}{c}\text { Depomedroxy progesterone } \\
\text { acetate (DMPA) }\end{array}$ & 51 & 19.8 \\
\hline Emergency Contraception (EC) & 37 & 14.39 \\
\hline Female sterilisation & 164 & 63.8 \\
\hline Male sterilisation & 63 & 24.51 \\
\hline Natural & 126 & 49.0 \\
\hline
\end{tabular}

Reasons for not using any method of contraceptives in the past was asked to each woman participating in the study and it was found that majority $(38.5 \%)$ did not use any method because of fear of side effects; 21 women (8.1\%) were ignorant about contraceptives and 64 (24.9\%) of them did not feel the need to use any method; 35 women (13.6\%) had some form of side effect, for which they discontinued the use (Table IV).

\begin{tabular}{|c|c|c|}
\hline Reasons & Frequency & Percentage \\
\hline Fear of side effect & 99 & 38.5 \\
\hline Ignorance & 21 & 8.1 \\
\hline Does not feel the need & 64 & 24.9 \\
\hline Husband staying outstation & 38 & 14.7 \\
\hline Unbearable side effect & 35 & 13.6 \\
\hline Table IV Reasons for & & \\
\hline
\end{tabular}

Table IV. Reasons for not using Contraceptives in the Past

Each and every patient was counselled before discharge from the hospital and was asked to accept some form of contraception to which majority agreed, but 28 (10.8\%) did not; 101 (39.2\%) women agreed to use condoms to prevent further pregnancy and $64(24.9 \%)$ wanted to take OC pills. IUCD was inserted in $33(12.8 \%)$ women. Bilateral tubal ligation was done in 27 (10.5\%) women who wanted to adapt a permanent method of sterilisation (Table V).

\begin{tabular}{|c|c|c|}
\hline Types & Number & Percentages \\
\hline Condom & 101 & 39.2 \\
\hline $\begin{array}{l}\text { Oral contraceptive pills } \\
(\text { (OCP) }\end{array}$ & 64 & 24.9 \\
\hline $\begin{array}{c}\text { Intrauterine contraceptive } \\
\text { devices (IUCDs) }\end{array}$ & 33 & 12.8 \\
\hline $\begin{array}{c}\text { Depomedroxy progesterone } \\
\text { acetate (DMPA) }\end{array}$ & 4 & 1.5 \\
\hline BTL & 27 & 10.5 \\
\hline No contraceptive & 28 & 10.8 \\
\hline \multicolumn{3}{|c|}{ Table V. Acceptance of Contraceptives after MTP } \\
\hline
\end{tabular}

\section{DISCUSSION}

There are a wide variety of modes of contraception available for the choice of a woman. These methods include natural methods, barrier, oral contraceptive pills (OCP), intrauterine devices (IUD), progesterone injections and the permanent methods like female and male sterilisation. In spite of the availability of this wide variety of contraceptives, $10.89 \%$ of women in our study did not accept any contraception even after counselling following MTP. In the study by Bhat et al after termination of pregnancy, $21.6 \%$ of women in their study were not able to decide about the choice of contraception as compared to $6.1 \%$ in another study by Srivastava $\mathrm{R}$ et al.[3][4]

The majority of abortion seekers were in the age group of 20 - 30 years $(64.2 \%)$. Similar finding was obtained in the study by Khiste $\mathrm{S}$ et al, where around two-third of the women (60\%) were in the above age group. ${ }^{[5]}$ While women of all age groups seek abortion in India, a review suggests that the majority of those seeking abortion are in the age group of 20 29 years. ${ }^{[6]}$ Adolescents both married and unmarried constituted $5.4 \%$ in our study group; $1 \%-10 \%$ of abortion seekers are adolescents as reported by Khiste et al.[5] This shows that younger women seek termination more frequently rather than older women, which may be attributed to lack of motivation and decision making among these younger women for accepting contraceptive measures either to postpone pregnancy or after completing the family. [7]

Majority of women, 175 (68.1\%) in our study already had two or more living children. This was also reflected in the study by Bansiwal et al.[8] These data reveal a trend towards a small family norm, especially in an urban setting like Bhubaneswar. But ignorance, lack of family support, social 
and religious factors and inadequate social welfare services probably affected their use of contraceptives.

Of the 257 women in our study group, only 21 (8.2\%) women were not aware of any form of contraception. Knowledge of contraception was more, but still non-use of a contraceptive at the time of conception was high (61.3\%) in the study by Bansiwal et al[8] as compared to that in the study of Aneblom et al (33\%) and Srivastava R et al (55.2\%).[9,4]

Majority of the women (96.9\%) in a study in Berhampur, knew about one or other methods of contraception. OCPs and female sterilisation were known to $96.9 \%$ of the women followed by condom (90.3\%). But only $48 \%$ of the women practised any one method of contraception. ${ }^{[10]}$

Awareness regarding permanent methods like female sterilisation and male sterilisation was $89.3 \%$ and $64.5 \%$ respectively in the study by Srivastava et al, ${ }^{[4]}$ while in the study by Bhat et al it was $52.6 \%$ and $27.8 \%$ respectively.[3] Our study reveals an awareness for female sterilisation as $64.5 \%$ and male sterilisation as $24.5 \%$.

Studies done by Mehra et al in Chandigarh (2003) and Tripathy et al (2004) found only one woman in both their studies who had knowledge about emergency contraceptive (EC).[11,12] In 2013, Rocca et al found 7.8\% of women in their study group who were aware of EC.[13] Awareness is increasing with 37 (14.4\%) women in our study who knew about EC. But this percentage is also very low and this is an area where publicity can help in preventing many unwanted pregnancies safely and conveniently. EC is particularly useful for those who are inconsistent contraceptive users.

The reason given by majority of the women in our study for not using contraceptives in the past was the fear of side effects (38.5\%); $24.9 \%$ of women felt that they did not need any form of contraception, as they were following the natural methods. In a study by Sharma et al, the common cause for not using any form of contraception were fertility-related reasons such as fear of side effects, desire for more children, religious beliefs and preference for male child.[14] Reasons for not using contraceptives varied in magnitude in different studies. Fertility-related reasons were found as the main reason by Das et al (38.9\%), Khokhar and Mehra (30.7\%) and Bhasin et al (36.4\%).[15,16,17] According to a cross-sectional study conducted by Mallini M Bhattathiry and Narayanan Ethirajan in urban Tamil Nadu, the prevalence of unmet need for family planning was $39 \%$ with spacing as $12 \%$ and limiting as $27 \%, 9 \%$ feared the side effects of contraception.[18]

Healthcare providers in India are inclined to offer abortion services with a precondition that the woman should accept contraceptives after the procedure. Rates of postabortion contraceptive use vary widely among Indian couples ranging from $75 \%$ to $93 \%$ among women interviewed in clinical studies and $50 \%$ to $58 \%$ in community studies.[19,20] However, these studies show higher rates of method discontinuation in short intervals following pregnancy termination. [19] In our study, all patients were counselled regarding acceptance of one or other method of contraception following MTP and the acceptance rate was $89 \%$. Majority of the women were willing to use condoms as a mode of contraception (39.3\%) followed by oral contraceptives $(24.9 \%)$. In the study by Uma Maheshwari $\mathrm{R}$ et al, adoption of contraception following termination of pregnancy was among 172 (93.5\%) study participants, which is similar to our study. ${ }^{[7]}$ This high acceptance could be due to repeated counselling in the hospital and also to a perceived feeling of the study participants that termination of pregnancy may not be done alone, especially for those who have completed their family. Studies done by Dhillon et al [20] and Shankaraiah et al[21] showed that the acceptance of postabortal contraception was only $50.4 \%$ and $48.9 \%$ respectively among MTP seekers following abortion.

In a study by Singh et al in New Delhi, permanent method of contraception was the most common, $45.9 \%$ (including vasectomy $0.9 \%$ only), which was higher than the national level (34.2\%). Adoption of permanent method (Tubectomy) among women aged $35-44$ yrs. 60.4\% (p < 0.001), women having living children more than two $57.9 \%(\mathrm{p}<0.001)$ and illiterate women $71.1 \%$ ( $\mathrm{p}<0.001$ ) was found to be statistically significant. This may be due to the fact that they had completed their family and were counselled to accept a permanent method. Most common motivation for adopting a contraceptive was self-motivation (47.6\%) followed by advice of a health worker (25.8\%), a doctor (13.9\%) and family members $(4.8 \%)$. Mass media did play a role in influencing for acceptance of contraceptives (7.9\%).[22]

In a study by Banerjee et al in 2011, they found that overall contraceptive acceptance after medical abortion was much higher in their study as a result of short-term method acceptance in conjunction with dispensing the first dose of medical abortion drugs. Thus, providing condoms and hormonal methods such as pills and injectables which can be offered on the first day of medical abortion in accordance with WHO guidelines (WHO 2009) appears to increase contraceptive acceptance following medical abortion. However, women who had surgical abortion were more likely to accept long-acting methods than those who had medical abortion. This variation may be explained by the fact that concurrent sterilisation and IUD insertion are more feasible after a surgical procedure, whereas providers often ask women receiving medical abortion to wait until their menstrual cycle resumes. This results in missed opportunities for women to receive effective methods as the return rate is low.[23]

\section{CONCLUSION}

The common reasons for women having an unplanned pregnancy were either a completed family or the previous child being too small. This suggests an unmet need of contraception in these women. Though the awareness of different methods of contraception is high, the actual acceptance rate is low. There is a need for community health education to reduce misconceptions about the side-effects of modern contraceptives, thereby helping them to accept and continue using various suitable methods of family planning. Above all the target group should be couples in the reproductive age group and not women alone. Vasectomy as a permanent method of sterilisation should be popularised more as an easy, quick and relatively safe method.

\section{REFERENCES}

[1] Lamina MA. Prevalence of abortion and contraceptive practise among women seeking repeat induced abortion in western Nigeria. J of Preg Article ID 486203, 2015;2015:7. 
[2] Faundes A. Strategies for the prevention of unsafe abortion. Int J Gynecol Obstet 2012;119(Suppl 1):S6871.

[3] Bhat PV, Prabhu A, Kumar P, et al. Contraceptive knowledge, practise and acceptance among women seeking termination of pregnancy at a secondary level hospital in southern Karnataka. Health and Population Perspectives and Issues 2008;31(3):157-62.

[4] Srivastava R, Srivastava DK, Jina R, et al. Contraceptive knowledge, attitude and practice (KAP) survey. J Obstet Gynaecol India 2005;55(6):546-50.

[5] Khiste S, Dank G, Rachkonda L, et al. Knowledge, attitude and practise (KAP survey) of contraception among women seeking termination of pregnancy at a tertiary care hospital in Maharastra. Int J Recent Trends in Sci and Technology 2015;17(1):10-3.

[6] Gupta S, Dave V, Sochaliya K, et al. A study on sociodemographic and obstetric profile of MTP seekers at Guru Govind Singh Hospital, Jamnagar. Healthline 2012;3(1):50-4.

[7] Maheswari UR, Jayanti TP. Abortion seeking behaviour: a study from tertiary care hospital. Int J Community Med Public Health 2017;4(7):2303-7.

[8] Bansiwal R, Singh P, Bajpai S. Practise of contraception in this modern world: still a myth? Int J Reprod Contracept Obstet Gynecol 2015;4(3):674-7.

[9] Aneblom G, Larsson M, Odlind V, et al. Knowledge, use and attitudes towards emergency contraceptive pills among Swedish women presenting for induced abortion. BJOG 2002;109(2):155-60.

[10] Padhy S, Nayak R, Tripathy RM. Study of sociodemographic profile and contraceptive use among married women attending an Urban Health Centre, Berhampur. Int J of Med Res Rev 2016;4(12):2211-6.

[11] Mehra R, Goel P, Dua D, et al. Knowledge of emergency contraception among women coming for induced abortion. J Obstet Gynecol India 2006;56(3):233-5.

[12] Tripathy R, Rathore AM, Sachdeva J. Emergency contraception: knowledge, attitude and practise among health care providers in North India. J Obstet Gynaecol Res 2003;29(3):142-6.

[13] Rocca CH, Shankar M, Sreevathsa A, et al. Acceptability and use of emergency contraception among married women in Banglore, India. Int J Gynaecol Obstet 2013;121(1):64-8.
[14] Sharma A, Sharma U, Acharya R, et al. Acceptability and practise of contraception and frequency of induced abortions in married women of reproductive age group, in a tertiary-care hospital. Int J Med Sci Public Health 2015;4(6):845-8.

[15] Das R, Amir A, Nath P. Utilisation and coverage of services by women of Jawan block in Aligarh. Ind J Community Med 2001;26(2):94-100.

[16] Khokhar A, Mehra M. Contraceptive use in women from resettlement area in Delhi. Ind J Community Med 2005;30(1):21-3.

[17] Bhasin SK, Pant M, Metha M, et al. Prevalence of usage of different contraceptive methods in East Delhi: a cross sectional study. Ind J Community Med 2005;30(2):53-5.

[18] Bhattathiry MM, Ethirajan N. Unmet need for family planning among married women of reproductive age group in urban Tamil Nadu. J Family Community Med 2014;21(1):53-7.

[19] Ganatra BR, Hirve SS, Karvande S, et al. Induced abortions in rural western Maharashtra. In: Koenig MA, Jejeebhoy S, Cleland JC, et al. (eds). Reproductive health in India: new evidence. $1^{\text {st }}$ edn. New Delhi: Rawat Publications, 2008:281-302.

[20] Dhillon BS, Chandhiok N, Kambo I, et al. Induced abortion and concurrent adoption of contraceptives in the rural areas of India: an ICMR task force study. Indian J Med Sci 2004;58(11):478-84.

[21] Shankaraiah RH, Annadani RR, Vijayshankar V, et al. Medical termination of pregnancy and subsequent adoption of contraception. Int J Reprod Contracept Obstet Gynecol 2013;2(3):367-71.

[22] Singh SV, Ingle GK, Gupta VK, et al. Socio-demographic profile of married women using contraceptive methods in a rural area of Delhi. Ind J of Com Med 2006;31(4):310.

[23] Banerjee SK, Andersen K, Tank J, et al. Evaluation of a network of medical abortion providers in two districts of Maharastra, India. Glob Public Health 2011;6(3):283-92. 